at all the known health resorts; sometimes they have

personal knowledge of the places, more often they have not.
The object I have in this paper is to give lists of concentrated statistics on weather in all the available English health resorts, in order that members of the profession might take them for what they are worth, and occasionally perhaps pick out some locality for special ailments, without regard to the reputation it holds in the eyes of some fashionable physician or in the eyes of the fashionable public. The general aspect of a town, and even of a single street or house, is in many instances worth a mile of statistics; no description on paper by any one man could ever satisfactorily convey to the minds of the public the aspects of a score of towns. I can speak for my own town, and can tell those who do not know Margate that they can find warm parts even in winter. The inhabitants group together on the southern and south-western sides of the town, leaving the more exposed Cliftonville district for visitors who like the cool breezes in summer. In most seaside towns there are warm and cold quarters, and the inhabitants and knowing visitors are the first to seek them out. From the figures I have tried to place in simple uncomplicated columns it will be seen that our English climate does not, after all. differ as much as is sometimes supposed, even in the farthest separated localities. Poets and cynics are never tired of proclaiming the unfathomable cbaracter and changeableness of woman. Some day a philosopher may arise who may be privileged to reveal the meaning of even these deep mysteries, but the mind cannot realise the possibility of any future sage penetrating into those distant and secret regions where sit the relentless deities who disarrange the weather of our suffering island. I hope that this paper may, in a small way, help to take the subject of the climate of our health resorts out of the region of mere hearsay, and enable the profession and the public to esteem at its right worth the silent but arduous labour of all those gentlemen in different parts of the kingdom, without whose un wearying industry these imperfect notes could not have been written.

Margate.

\section{CAVERNOUS ANGIOMA OF THE CHEEK; ITS SURGICAL CURE.}

\section{By E. BOTTINI,}

PROFESSOR OF OPERATIVE SURGERY IN THE VNIVERSITY OF PAVIA.

BY "cavernous angioma" we understand a tumour formed by ectasic or varicose veins. Porta, in his learned monograph on "Angectasia," read at a meeting (Feb. 7th, 1861) wh the Lombardo-Venetian Institute, defines the tumour as "angectasia venosa," and rightly observes that it has its ordinary seat in the mucous membranes and relative cellular tissue. Hueter, in his admirable "Surgery," remarks that in the cheek the development of the submucous veins assumes a special preponderance, readily transforming itself into "angioma venosum," or rather into cavernous venous tumour (der cavernosen Venen Geschwulst). This tumour finds its natural exemplar in the structure of the corpora cavernosa of the penis, with this difference, however, that the lacanæ or vascular alveoli are in the neoplasm more unlarged. More than any other angioma, it runs an aggressive course, attacking and destroying the more adjacent tissues, to acquire for itself the space necessary for its everincreasing proportions. In this work of demolition it respects neither aponeuroses nor muscles, but corrodes and uses up even the cartilaginous and osseous structures. Given a tumour of this kind in the cheek, and it is easy to understand its rapid development; equally easy to imagine the ravages it can inflict on the soft parts which can offer it no effective resistance. And therefore the need of providing such resistance is imposed on us, not so much to repair the unsightly disfigurement as to guard against a serious-nay, a grave-menace to life itself. Surgical intervention, so rich in effective resources against capillary angiomata, "telangectasiæe," and erectile tumours with an arterial basis, has up till now shown but a feeble front against " angiomata varicosa." The bistoury, which is vaunted by many surgeons as the chief among curative agents in "angectasia," cannot be employed in the alteration in question, not only because of the grave hæmorrhage, but because of the enormous loss of substance which can in no way be made good. Porta recommends the use of the seton, and calls it a " rational means ; not always, however, effective." It is no: necessary to demonstrate that, if that expedient could be discussed in his day, when the antiseptic system was unknown, its claims could not possibly be vindicated now. Nor shall I waste time by enlarging on the worth of any other proposals, which, if serviceable in other varieties of angioma, did not, and do not now, possess any value in that particular angioma we are considering.

I cannot omit from mention that in the medical journals, from time to time, there have appeared laudations of the advantages of electrolysis. Even, however, where it makes a partial approach to the end in view, I am convinced that it does so rather by its electro caustic than by its electro. chemical virtue. I know this expedient, and, indeed, remember to have employed it on more than one occasion, but always with the same disappointing results. In this connexion I may cite my first clinical observation on cavernous angiomata, described by me at page $19 \mathrm{l}$ of $\mathrm{my}$ paper on the "Galvano-caustic Treatment in Practical Surgery." The case was that of a boy of thirteen, now one of the most distinguished professors in the Faculty of Natural Science in the University of Turin. He was affected with cavernous angioma invading all the left cheek, and on this were fruitlessly expended all the remedial agents suggested in such cases, not only by Italian surgeons, but even by the most celebrated among those of other countries. On this boy electrolysis was practised during some thirty sittings, and all without the slightest benefit; nay, if we may believe his mother, with sensible and manifest injury. Then it was, and in this very case, that the idea occurred to me of transfixing the tumour in its greatest diameter, planting in it pins of platinum, and rendering them incandescent by means of an electric battery. This expedient, which affords, if you like, a far-off reminiscence of the seton suggested by Porta, yielded a brilliant response in the disappearance of the tumour, with this drawback, however, that it left behind disfiguring puncture marks.

In 1878 , in private practice, I met with a similar casethat of a girl aged seven, the daughter of tenant-farming parents resident at Confienza, in the province of Vercelli. Here, too, I adopted the same practice - that is, to transfix the tumour throughout with a tubulated needle, and, having removed this, to leave a platinum pin, which was immediately made red.hot, the number of the pins varying from four to six, inserted in a transverse as well as in a vertical direction. The coagulation of the blood ensued forthwith, and the detachment of the escbar never caused the slightest loss of blood. The tumour gradually disappeared by absorption, leaving, however, in this case also a group of whitish cicatricial spots, not conducive, certainly, to female beanty. It was then that, with a view to avoid the after disfigurement, and reflecting that the setaceum candens acted only by coagulating the san. guineous mass in the lacunæ of the tumour, I decided, on the first opportunity, to have recourse to coagulating in. jections, as conducing to the same result, with an imperceptible capillary aperture, which could be effected from the oral cavity. I had no early opportunity of again practising this expedient, as cavernous angiomata in the cheek, without being very rare, are not to be met with at will.

In February, 1888, there was in the Operative Clinte of Pavia a case, a female child about three years old, affected with venous angioma of the right cheek. The tumour was of small proportions, with a diameter not quite so large as that of a florin. I made use of the Pravaz syringe, and, as a coagulating liquid, of Piazzi's mixture, for some time employed with decided success in the wards. (As is known, it is composed of equal parts of a saturated solution of chloride of sodium in water and of a neutral solution of perchloride of iron at $20^{\circ}$ Beaumé.) I made three injections at equal distances in the body of the tumour, proceeding from the oral cavity. The child gave a convulsive cry, contorted herself, became cyanotic, then asphyxiated, the respiration and the cardiac rhythm soon coming to a standstill. All our efforts to reestablish natural by artificial respiration were, unfortunately, without avail. At the necropsy we found the tumour solidly occupied by coagulated blood; emboli in the peripheral veins; no embolus, however, in the external and internal jugular; heart empty. This first attempt, so quicklv fatal, was enough to make me shrink from repeat- 
ing the experiment. Therefore I decided in analogous circumstances to return to the first method, remembering for my own benefit, "Come il meglio sia nemico del bene" (how the "better" is the sworn enemy of the "good").

At the close of last year a young woman twenty-three years of age, one $G$. F - came to consult me privately. She was affected with a cavernons angioma of the left cheek, invading all its muscular thickness as far as its cutaneous integument, which was of a violet colour. The tumour, besides, protruded outwardly into the oral cavity, and, unable to confine itself within the orifice, passed over the margin of the teeth, so that the young woman was obliged for some time to keep the mouth half shut so as not to squeeze the tumour, which penetrated from one dental arch to the other. She suffered frequent hremorrhages, either spontaneous or provoked by a tiny wound, and therefore presented a notable oligæmic aspect. With every wish to recur to the galvano-caustic treatment for this angioma, I reflected whether it was not a case for so guarding the procedure as not to leave unsightly traces, which in a young woman would have been deplorable, to say nothing of their publicly revealing the shortcomings of our art. So I decided on entering by the oral cavity into the body of the tumour with the lancet-shaped galvanic knife, and, carrying it from above downwards by a "to-and-fro" movement, and from without inwards, on forming a necrotic cross which should enclose the circuit of the tumour. The woman was anæsthetised ; and just above the left labial angle, opening a passage in the sound mucous membrane, I reached with the incandescent lancet the bulk of the tumour, pushing the cautery as far as the upper pole; then with an up and down movement I practised a true cleavage in a vertical direction. Reintroducing the instrument into the centre of the tumour, I turned back the blade in the horizontal plane, and, with a double movement sideways, I made another horizontal section. The blood was distinctly heard frizzling in the body of the tumour, and with a jet of smoke there came out on the steel a Jittle clotted blood. On removing the instrument the tumour had become entirely solid and somewhat diminished in bulk. The woman, having awoke, was put to bed again with only the application of cold water and vinegar to induce a calmative effect. I need not give a detailed report of the case, which in less than a month succeeded perfectly. The woman left the wards completely cured, not only from the angioma, but also from the semi-ankylosis of the mandible, for which during her anæsthetised state I had practised mechanical dilatation. Before coming to the Congress I got my assistant, Dr. Ferrara, to call on the young woman, who had been operated upon, for re-examination, and I was glad to note all the best signs of a complete and satisfactory cure.

With this modification - that is, replacing the setaceum candens by the thermo-galvanic knife-we succeed in obtaining a satisfactory cure without leaving any perceptible puncture marks, thus realising the best and the highest therapeuticideal. And this proced ure, which favoured me in so propitious a manner, I am now happy to make known to my colleagues of London, in the hope and expectation that in their hands it will be no less salutary. In the poverty of really effective expedients against a malady which when neglected issues inexorably in the sacrifice of the patient, you will certainly receive with favour a proposal which solves successfully the problem of associating the beautiful in art with what is beneficial to the patient.

As the subject admits of it, allow me to show you a new accumulator battery recently devised by me for a thermogalvanic purpose. You are aware that the galvanic "dieresis,"notwithstanding therecommendations of Middeldorf, Voltolini, Maas, and Paul Bruns, was not cordially received by the practical surgeon, and was, I will not say mutilated, but decapitated by the introduction of the thermo cautery of Paquelin ; and yet the services capable of being rendered by the thermo-galvanic a gency are a thousand, nay, twice a thousand, times superior to what you can get out of the Paquelin instrument. Not, indeed, because with this latter you cannot turn to good account the thermic handle, the principal factor of the bloodless "dieresis," but beeause with the thermo-galvanic agency you can introduce an instrument into the oral as well as into the uterine cavity, even into the neck of the bladder, in a perfectly cold state; apply it in the proper position, and, when you have satisfied yourself as to the regular agreement, set fire to it; while, with the Paquelin, you have to carry into its destined position the already red-hot instrument, and thus expose yourself to cauterising and destroying all the tissues you happen to touch. This singular modus agendi of the electric cautery places it far above its other congener ; and yet, I repeat, all surgeonsnot without reason, be it said-looked with favour on the Paquelin instrument, while few troubled their heads with the galvano-caustic. And why? Because the galvanocaustic instrument, in the manner in which it is now contrived, even by those who have bestowed special study and particular favour, on it, requires, in the selection and. control of the electro-generative apparatus, a series of delicate and minute attentions which the surgeon cannot always give; add to this that, notwithstanding the most scrupulous care, one cannot always be sure that its action. may not let loose a series of disturbances from the quality of the acids, more or less impure, and notably from the nitric acid; from the imperfect amalgam of the zincs; and from the more or less thorough washing of the carbons and the porcelains, so that the surgeon is uncertain and apprehensive as to the mode in which the machine properly works-a mode which he cannot in any way rectify when it fails, but can only abandon it and return to the ordinary "dieresis. These imperfections in the electric production suggested different batteries, pressing well-nigh all the known systems into the service. 'Thus from the highly expensive Grove battery, which Middeldorf employed, one came down to the more economic battery of Bunsen, while this gave place to a third one yet more simple, that of the oxidated iron of Paul Bruns. Then came all the one-liquid piles with variants more or less happy of the Grenet type.

Having made ourselves familiar with all the piles sug. gested, with a one-liquid and a two-liquid pile, we must abandon the one-liquid ones (that is, the pile with the solution of bichromate of potash) since their action is capricious, imperfectly disciplined, excessive in the first contacts, then too feeble after some minutes. Unable, therefore, to have a constant and uniform current, one cannot have a constant and uniform heating-process, and therefore a disciplined thermic action necessary for the object in view. Of tho other two-liquid piles, the best incomparably is that of Bunsen modified by Pischel of Breslau, and of this I have now unade use for twenty years. I do not deny that, though it is the best among those known to us, it has notable defects, specially attributable to the accurate control it demands and to the density of the acids it requires to obtain a prompt and intense action, acids not always to be found at the chemist's. The vapours, moreover, of nitrous acid, besides offending patient and surgeon, attack and spoil every metallic instrument lying in the operating room. Many duties, which we cannot ourselves attend to and have to delegate to servants, are of ten carelessly performed, such as the washing of the carbons and their thorough drying; and then the activity of the battery leaves much to be desired. More than once have I found myself in such difficulties, and I can quite understand the profouno annoyance they may occasion. I grant, therefore, to all my colleagues the full benefit of extenuating circumstances if they end by turning their backs on the galvano-caustic instrument, and by viewing with favour the Paquelin thermo-cautery, which cannot in reason have any claim to be preferred; just as I pardon Billroth when for the blood less "dieresis" he wrote: "That the public practitioner, between the galvanic handle and the linear contusion, har decided for the latter," an opinion which at the present moment would appear a paradox.

Desirous, therefore, of rectifying the imperfections which in the use of the galvano-thermic instrument arose from the electric source, I set myself to study the use of the accumulators. I cannot but admit that the first trials were far from encouraging, not only when made at an electric establishment of high reputation air Milan, but also when carried out at the Industrial Society's Institution at Lodi, directed by the distinguished engineer, Signor Ceresa. These experiments, horrever unsuccessfu? in their result, nevertheless convinced me that the con ception was capalsle of being realised with a proper mode $o^{\prime}$ distribution. The problem I had set myself was this: To have at command an electric power considerable enough to be susceptible of distribution in a constant, unalterabla manner, according as necessity arose-that is to say, without shocks, without loss of equilibrium, and without stoppages. This force should work for a long time-for several hours- 
as long, in fact, as might be required for a complex and protracted operation. It was then that, having gone to Lodi to Ingr. Ceresa's institution, after unsuccessful experiments with other machinery, it occurred to me to replace the Bunsen elements of the pile (Pischel's model) used by me by other accumulators perfectly closed, to be reunited in a plane of distribution graduated by means of ordinary column commutators. Ing. Ceresa and Professor G. Gandini, director of the Laboratory of Physics in the Lodi Lyceum, fully grasped my idea in constructing the battery. I have had the honour of presenting to the last meeting of Surgery, held in Florence on April lst of the present year, a battery which perfectly corresponds to techinical requirements. It consists of four accumulators which yield an electro-motor force fully three times stronger than the respective couples of Bunsen, and which can remain operative for quite twenty. four hours without loss of intensity or of tension. The arrangement is simple, costs very little, receives its charge easily either with a dynamo (and in a few minutes) or with one or more couples of the Bunsen or any other pile. The distribution is made with the column commutators and, if need were, chain commutators might serve, as indeed they have done. The battery remains charged for many months, and may, as necessity arises, be employed immediately, without any preliminary trouble. The several accumulators are hermetically closed, and may be turned over without spilling a Arop of liquid, and yet there is no emanation of any sort. The battery is, moreover, easily transportable. With this ottery, which the surgeon may have al ways handy and fully charged in his own laboratory, and which, as it stands, can be transported anywhere with its activity constant and unimpaired, be can meet with promptitude any eventuality imposed on him by urgent necessity ; and, from this point of view, the novel apparatus is yet handier, more expeditious, and more certain than Paquelin's. When its action is no longer wanted, you have nothing to do but shut the lid of the battery and it is as ready as ever for another occasion. I do not know that anything can be devised more simple, more active, and, let me add, more economical, inasmuch as the four accumulators do not cost more than 50 francs $(£ 2)$ in all.

At present Signor Ceresa is making me another battery on a reduced scale, equally $\epsilon$ nergetic and efficacious, with the riew of rendering it, in the vicissitudes of daily practice, easily carried about in the hand. For the glass vases will be substituted wooden ones, which will lessen the risks of breakage in transport. Permit me to tender one word of praise to the distinguished directors of the Lodi Institution who so readily interpreted my idea without obliging me to have recourse to the industrial establishments abroad. The problem as to the source of the electro-caustic battery having been so resolved as to leave nothing to be desired for simplicity and effectiveness of working, I fully cherish the hope that the surgical world, abandoning other substitutes, will readily avail itself of the galvanic "dieresis." I do not suppose that recourse ought ever to be had to the galvanic "dieresis" when the ordinary battery will suffice, but I maintain that in circumstances In which the latter is either not applicable or liable to grave inconveniences it should be replaced by the thermogalvanic. In the endo-vaginal amputation of the cervix, in that of the tongue, in amputation of the penis, in removal of voluminous hæmorrhoidal masses, surgery can point to no substitute which offers the advantages of the galvanic "dieresis."

With a sectio quite bloodless, wellnigh painless, aseptic in the absolute meaning of the word, during and after the operation, since with handle or with incandescent knife you employ the most aseptic instrument of "dieresis" imaginable on living parts, you have an eschar which, better than epithelium or epidermis, acts as a shield against putrid contamination. So that with the action of the galvanic "dieresis" prudently confined to those cases in which it claims a merited preference, and with the electrogenous apparatus rendered simple, handy, and certain, the surgeon is provided with an instrument calculated to yield advantages attainable by no other means.

Female District Medical Officers in Russia.The Russian Minister of the Interior has issued a circular Informing provincial administrative bodies that female practitioners may be appointed district medical officers With charge of the district hospitals.

\section{ADENOID GROWTHS IN THE NASO- PHARYNX, COMMONLY CALLED POST-NASAL GROWTHS. ${ }^{1}$}

\section{BY W. R. II. STEW ART,}

AURAL SURGEON TO THI GREAT NOITHERN CEYTRAL HOSPITAL; SURGEON TO THE LONDON THLOAT HOSPITAL.

I PRopose in this paper to make a few remarks about adenoid growths in the naso-pharynx, commonly called post-nasal growths. I think this subject is one that should claim the special interest and attention, not only of aural surgeons, but of every practitioner of medicine and surgery, from the fact that, although it is very common, is easily diagnosed if properly looked for, and as easily got rid of if properly treated, the whole future health and prosperity of a child are at stake if the existence of these growths is not recognised and a correct line of treatment carried out; and yet the fact remains that their presence is often overlooked. The obstruction this disease causes to the proper performance of normal respiration prevents sufficient air from entering the middle ear through the Eustachian tubes, and the balance of equilibrium being thus upset, the atmospheric pressure drives in the drum-head, and this pressure, being conducted along the chain of ossicles, is exerted on the fluid contents of the labyrinth, causing a tension that will produce a most distressing tinnitus, accompanied at times by vertigo. The irritation, too, caused by both the growths and the habit of oral breathing to the mouths of the Eustachian tubes will produce an inflammatory condition, which spreads up the tubes in to the cavity of the tympanum, causing that chronic catarrh so fatal to good hearing, and which by the swelling of the lining membrane of the tube shuts in all secreted mucus and inflammatory products; these will become hardened around the ossicles and tympanic cavity, and produce the consequent permanent deafness and tinnitus; or, again, a suppurative condition of tine middle ear, with a perforation, and all its serious and at times even fatal sequelre, may result. The ear, however, is not the only organ of the body that is affected, for the chest, the teeth, and even the brain may suffer, and a permanent delicacy of constitution be established. The chest is affected in both its walls and contents ; the deficient amount of air in spired causes the walls to fall in; theintercostal spaces become deepened and the cartilages deformed, producing a form of pigeon-breast ; whilst the unfiltered and unwarmed air passing by the mouth only carries cold and impurities to the lungs, to breed disease in those organs. The teeth, exposed to the drying influence of the air, especially at night, when the mouth is wide open for hours without being even temporarily closed, becorne the resting-place of various microorganisms, and these, not being washed away by the saliva, acted on by the lips and cheeks, produce caries, whilst a lofty palate and contracted dental arch are frequently seen accompanying this disease. That the brain may be affected is palpable, from the semi-idiocy of manner and expression, and the peculiar shuffling walk so often seen in these cases The growths, which seem to be more partial to the males than the females, are essentially a disease of childhood and early youth, the largest number of cases occurring between the ages of six and nine; and out of over eighty cases operated on by me last year, the youngest was three and the eldest sixteen years old; but on the 28th of last month I removed the growths from a woman of twenty-seven years kindly sent me by Mr. Quick, and some two years ago I operated on a woman who had reached the age of twentyeight. This latter is, $I$ believe, a limit record. The greater number of children are in various stages of ill health, from the ordinarily speaking delicate child to the thin, pale, scrofulous one so of ten met with in the out-patient department; but, on the other hand, some are quite healthy and ruddy-looking.

The disease is generally congenital, and dampness in both residence and atmosphere seems to be conducive to its development ; and although, among the eighty cases I had last year, in only one instance two brothers, and in another a brother and sister, were affected; yet at times whole

1 A paper real before the Northern Division of the Metropolitan Counties Branch of the British Medical Association, May 8th, 1890 